Research Article

\title{
A Comparative Study on Structural, Morphological, and Tensile Properties of Binary and Ternary Epoxy Resin-Based Polymer Nanocomposites
}

\author{
Dalia M. T. Mustafa, ${ }^{1}$ Sarkawt Rostam $\mathbb{D}^{1},{ }^{1}$ and Shujahadeen B. Aziz $\mathbb{D}^{2,3}$ \\ ${ }^{1}$ Department of Mechanical Engineering/Production, College of Engineering, Sulaimani Polytechnic University, Sulaimani, \\ Kurdistan, Iraq \\ ${ }^{2}$ Advanced Polymeric Materials Research Lab., Department of Physics, College of Science, University of Sulaimani, Qlyasan Street, \\ Sulaimani, Kurdistan, Iraq \\ ${ }^{3}$ Department of Civil Engineering, College of Engineering, Komar University of Science and Technology, Sulaimani 46001, \\ Kurdistan, Iraq
}

Correspondence should be addressed to Shujahadeen B. Aziz; shujaadeen78@yahoo.com

Received 22 June 2020; Revised 30 July 2020; Accepted 31 July 2020; Published 19 August 2020

Guest Editor: Guian Qian

Copyright (c) 2020 Dalia M. T. Mustafa et al. This is an open access article distributed under the Creative Commons Attribution License, which permits unrestricted use, distribution, and reproduction in any medium, provided the original work is properly cited.

\begin{abstract}
In the present work, epoxy resin-based nanocomposites (NCPs) were fabricated with improved mechanical properties. The epoxy resin (EPR) was mixed with differing amounts of calcium titanate $\left(\mathrm{CaTiO}_{3}\right)$ nanoparticles $(\mathrm{NPs})$ and glass fiber. The results showed that the ternary system contained glass fiber exhibits low mechanical performance compared to binary $\left[\mathrm{EPR}^{\mathrm{C}} \mathrm{CaTiO}{ }_{3}\right]$ system. The effect of fiber glass and NPs on the epoxy resin mechanical behavior was determined by conducting a tensile test for various specimen sets. From the mechanical characterizations, it was seen that there is a monotonic relationship between the NPs concentration and Young's modulus. Additionally, NCPs samples were brittle in nature and the strain rate significantly decreased upon the addition of $\mathrm{CaTiO}_{3}$ concentration; while the tensile strength was increased. From the X-ray diffraction evaluation, it can be concluded that the addition of NPs have a great impact on the epoxy structure. Besides, the morphology appearance was in good agreement with structural and mechanical analysis.
\end{abstract}

\section{Introduction}

Recently, structural adhesives, coating compounds, composite matrices, coatings, and other technical applications make extensive use of epoxy resins. When it comes to automotive and aerospace industries and similar applications, composite structures are increasingly being manufactured with the help of resin transfer molding [1]. In aerospace military applications weight is a crucial point; thus, composite materials are considerably helpful since they have better specific stiffness (stiffness to weight) and specific strength (strength to weight) compared to conventional materials. Recent structural applications demand novel materials; therefore, nanomaterials and polymer composites have been widely investigated and developed [2]. There is also an escalating need for materials having high exceptional mechanical properties since polymer and its composites are being greatly used [3]. In terms of the novel composite materials, which are NCPs, they have a constituent whose dimension hails between 1 and $100 \mathrm{~nm}$. Molecular scale interactions give material enhancements to nanocomposite materials, which influences material and physical parameters at scales unreachable with conventional filler materials $[1,4]$. Polymers have been getting reinforcements in the form of organic or inorganic fillers for tens of years. Recently, polymeric NCPs are getting increasingly manufactured with the help of NPs as reinforcements. Nanofillers (NFs) will have different properties if mixed with matrix properties. Researchers are conflicted on whether matrix properties are enhanced or there is a negative impact due to 
the addition of NPs $[5,6]$. As expected, natural or artificial inorganic compounds were present in polymeric materials for many reasons such as reducing its price. Otherwise, its properties such as electrical conductivity and permeability for gases such as oxygen or water vapor are decreased. Alternatively, other properties that include heat resistance, impact resistance, and mechanical strength are improved. Plate-formed particles (such as mica), fibers (such as fiberglass), and materials (such as calcium carbonate) existing in the particle form are known as traditional fillers $[5,7]$. Numerous works have been published to enhance the toughness of epoxy composites. Inorganic nanoparticles, thermoplastic materials, rubbers, and other kinds of fillers having varied chemical natures are served as a third component to the epoxy systems as they were mixed. Because of this, the thermal and mechanical properties were enhanced to a great extent [8]. The impacts concerning NPs such as $\mathrm{TiO}_{2}$ [9, 10], ZnO [11], clay [12], multiwalled carbon nanotube (MWCNT) [13, 14], $\mathrm{SiO}_{2}$ [15], and $\mathrm{Al}_{2} \mathrm{O}_{3}$ [16] have been investigated in a number of research studies. Previous studies revealed that various factors affecting the mechanical properties of materials [17-20]. The fatigue crack propagation and statistical distribution of microcracks are well studied by Qian et al., [17, 18]. The development of He implantation-induced imperfections and dissimilar irradiation temperatures are also reported as factors that affect the materials properties $[19,20]$. By looking at the literature both intensively and extensively, it can be seen that numerous industrial applications (particularly, electronic applications) have deeply utilized the epoxy resins due to their superior fatigue life and above-average specific strength/ stiffness. With that being said, electrical and thermal conductivity, thermal expansion, and mechanical properties, with manifold functions necessitate more enhancements for some high-level applications [21].

As of late, researchers could be seen becoming increasingly interested in polymer nanocomposite creation. Accordingly, this research is aimed at investigating the mechanical properties concerning epoxy resin incorporated with $\mathrm{CaTiO}_{3}$ nanoparticles and glass fiber.

\section{Experimental Methodology}

2.1. Materials. The Don Construction Products (DCP) company was consulted for purchasing the quick mast 105 epoxy resin. The purchased epoxy had greater than or equal to $25 \mathrm{MPa}$ tensile strength, greater than or equal to $45 \mathrm{MPa}$ flexural strength, greater than or equal to $70 \mathrm{MPa}$ compressive strength at a week with $25^{\circ} \mathrm{C}$ temperature, around $50-70 \mathrm{~min}$ of pot life with $25^{\circ} \mathrm{C}$ temperature, VOC smaller than $20 \mathrm{G} /$ liter, $5^{\circ}$ lowest application temperature, $3-5$ poise viscosity with $25^{\circ} \mathrm{C}$ temperature while $1-2$ poise with $35^{\circ} \mathrm{C}$ temperature, and $1.1 \pm 0.05$ density. The $\mathrm{CaTiO}_{3}$ nanoparticles (purity 99.9\%) with a diameter of $30 \mathrm{~nm}$ were used with the epoxy resin to prepare polymer nanocomposites. The chopped fiberglass was obtained from commercial sources. The chopped glass fiber was supplied by Dost Kimya (DK) company and with an application temperature limit of $-60^{\circ} \mathrm{C}$ to $650^{\circ} \mathrm{C}$, specific gravity $2.60 \mathrm{gr} / \mathrm{cc}$, and fiber diameter of 13-15 microns.
2.2. Equipment. Nanoparticles, fiberglass, hardener, epoxy, and other such materials underwent the weighing process with the help of the digital balance scale (Sartorius-German origin). The epoxy composite acquired homogeneous dispersion with the help of BOECO Germany's magnetic stirrer that could run at $1500 \mathrm{rpm}$ at best. The furnace KAROL type alongside a thermostat was used to heat the specimens. Afterward, the specimens were tested with the help of a Cussons technology universal testing machine of $100 \mathrm{kN}$ maximum load. At room temperature and $5 \mathrm{~mm} / \mathrm{min}$ crosshead speed, the machine was used for tensile testing according to the ASTM D638 standard (Figure 1).

2.3. Fabrication of Nanocomposites. The filler/epoxy matrix NCPs were fabricated with the help of a facile method. Beakers that had magnetic stirrer bars were used for sample preparation. A 2:1 ratio was considered for fixing the hardener and epoxy resin mixtures. Three sets were prepared: (1) the magnetic stirrer was used to prepare pure epoxy; (2) epoxy with nanoparticles; and (3) nanoparticles, chopped fiberglass, and epoxy. The magnetic stirrer was used for carrying out the mixing method with a speed of $750 \mathrm{rpm}$ and $1500 \mathrm{rpm}$ in the first and final steps, respectively. The diamine curing agent and epoxy resin were kept in the beakers. Afterward, epoxy resin NCPs were prepared by adding $\mathrm{CaTiO}_{3}$ nanopowder in different amounts. 1, 3, 5, and $7 \mathrm{wt} . \%$ were the amounts of the nanocomposites' filler. Then, the epoxy resin lost some of its viscosity through heating so that the agglomerations do not form. A reduced pressure was considered for degassing overnight.

Appropriate molds were used for containing mixtures and ambient conditions were considered for conducting the curing process that lasted a week alongside a postcuring process for 7 hours with $95-100^{\circ} \mathrm{C}$ temperature. With the utilization of a laser CNC cutting machine, acrylic was used for making the mold. A lubricant was utilized for simply removing the mixture of epoxy from the mold after curing. The research also involves studying the fiber-reinforced epoxy resin polymer NCPs. The epoxy was mixed with the chopped fiberglass with (5-10) min of stirring and heating at $(95-100)^{\circ} \mathrm{C}$. Afterward, there was the addition of nanoparticles (with 5-10 min of stirring) and hardener (with 23 min of stirring). Normally, epoxy-based composites are cured with the help of primary amines. Furthermore, there can be dissimilar properties in epoxy resins upon combining and curing them using different curing agents. The amine's loading amount and type determine the curing speed. Some of the curing agents include aliphatic and aromatic compounds [22-25]. Under the room temperature and $5 \mathrm{~mm} /$ min crosshead speed, there was a tensile test for determining the mechanical properties concerning the nanoreinforced epoxy. The ASTM D638 standard was considered for conducting the tests of these specimens. Figure 2 schematically presents the curing procedure. For the binary system which consists of pure epoxy resin and nanocomposites, the samples were coded as EPR 0 and $\mathrm{EPR}+\mathrm{xCaTiO}_{3}$ $(0.01 \leq x \leq 0.07)$. For the ternary samples, the systems were coded as EPRGF0, EPRGF1, EPRGF3, EPRGF5, and 


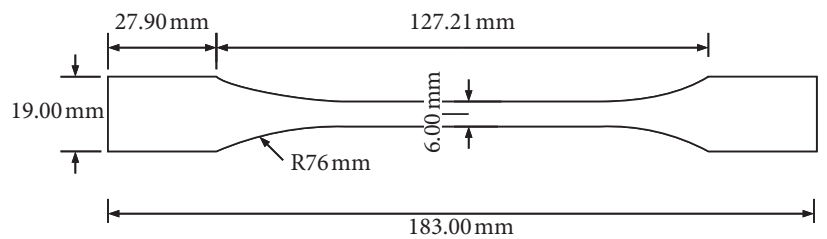

FIgURE 1: Dimensions of tensile specimen according to ASTM D638 standard.

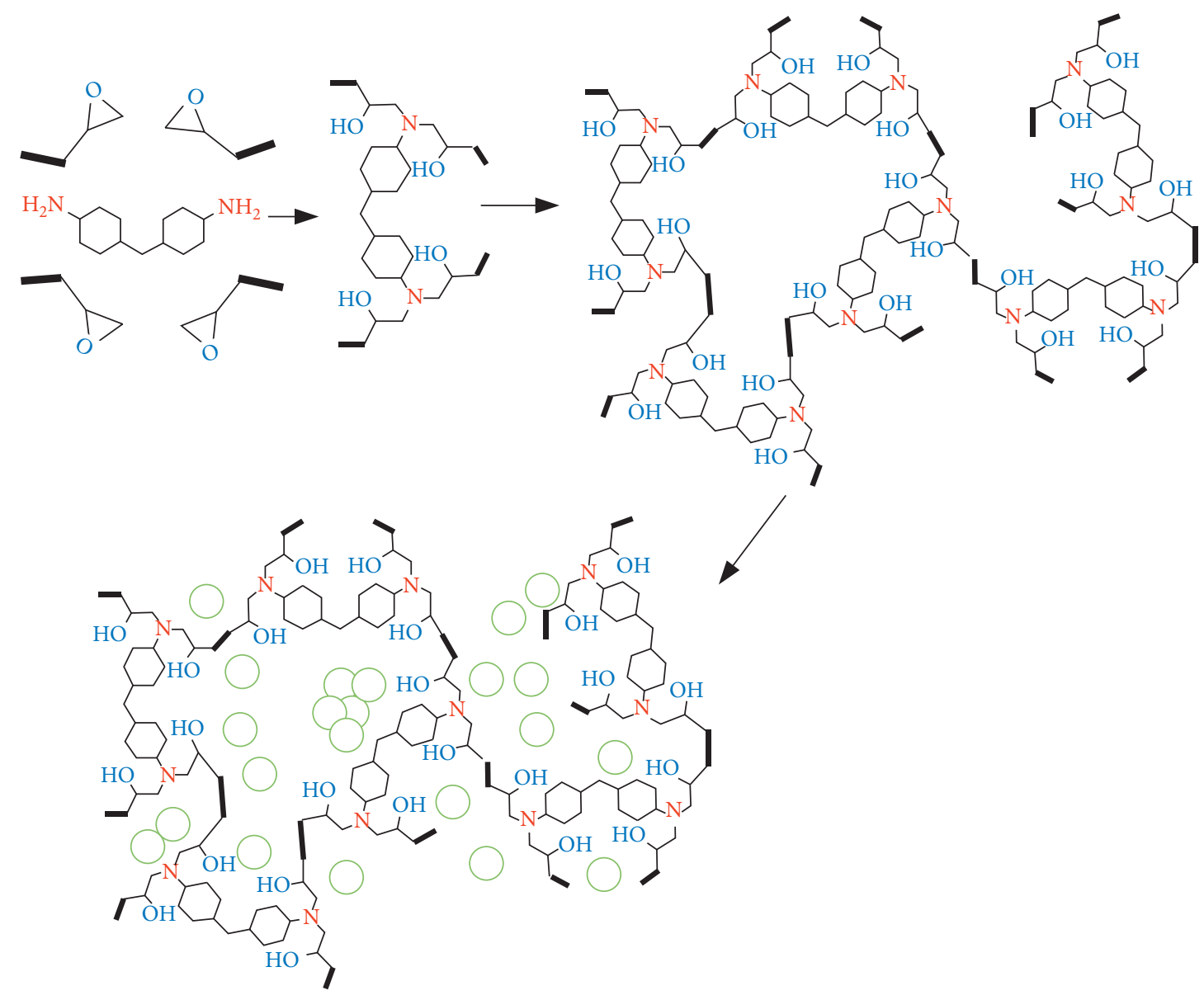

: Nanoparticles

FIGURE 2: Schematic representation of the curing process of nanocomposites.

EPRGF7, and for Epoxy resin (EPR), 0.01 wt.\% and 0.02 wt.\% fiberglass (GF) incorporated with 0 wt.\%, 1 wt.\%, 3 wt.\%, 5 wt.\%, and 7 wt.\% of $\mathrm{CaTiO}_{3}$, respectively.

\section{Results and Discussion}

3.1. XRD Analysis. The XRD pattern of the pure epoxy resin is shown in Figure 3. According to a variety of reports, the XRD evaluation can help with observing the NPs dispersion and the extent to which they exfoliate/intercalate within the epoxy resin matrix [21]. Earlier research studies are shown that there are wide peaks in pure epoxy resins. Each pattern demonstrated broad diffraction from $5-80^{\circ}$ alongside a couple of maxima close to $20-45^{\circ}$ as the cured epoxy network scattered and its amorphous nature revealed $[8,21]$. Nevertheless, when the epoxy matrix experienced $\mathrm{CaTiO}_{3}$ dispersion, the XRD pattern of epoxy NCPs demonstrated the epoxy diffraction peaks with poor intensities. Additionally, the enhanced sharp diffraction peaks of $\mathrm{CaTiO}_{3}$ with improved intensities were detected, as shown in Figures 3(b) and 3(c). This is not the case with epoxy XRD pattern particularly when the $\mathrm{CaTiO}_{3}$ nanoparticles are highly concentrated. According to prior research studies, it is true that the attraction between surface groups of nanofiller (NF) based on Coulomb and van der Waals forces is responsible for aggregating NPs with high concentration $[24,25]$.The maximum intensity for pure epoxy resin is about 250a. While it reduces to around 100 a.u at 3 wt.\% of 


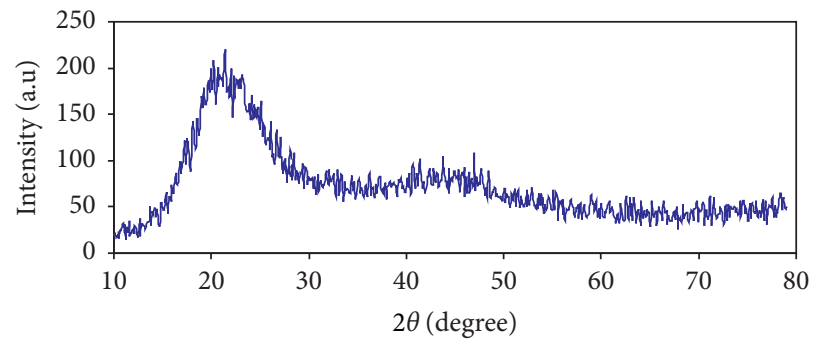

(a)

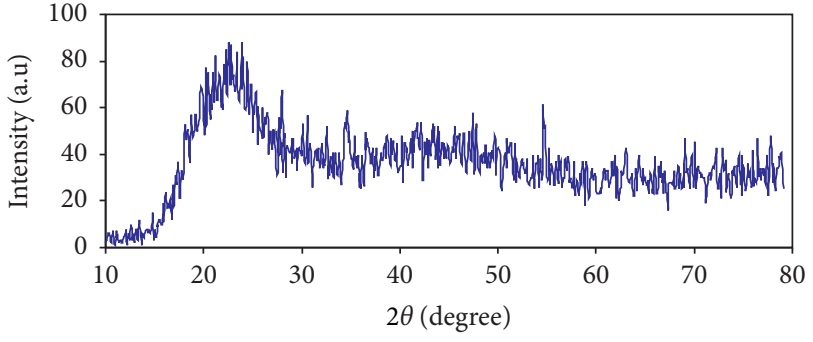

(b)

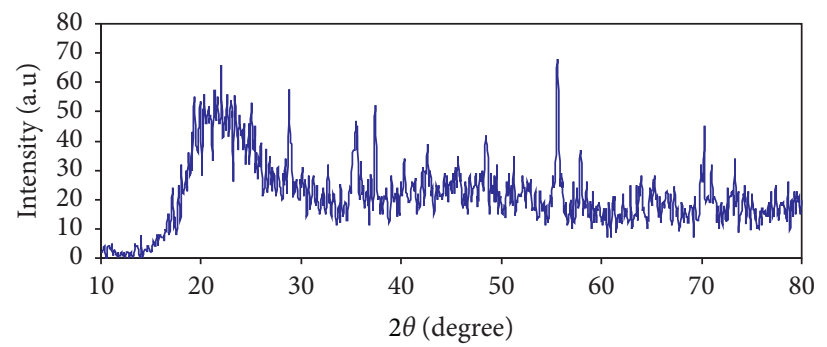

(c)

FIgURE 3: XRD pattern for (a) pure epoxy resin (EPR0), (b) $\mathrm{EPR}+3$ wt. $\% \mathrm{CaTiO}_{3}$, and (c) $\mathrm{EPR}+7 \mathrm{wt} . \% \mathrm{CaTiO}_{3}$.

$\mathrm{CaTiO}_{3}$ and finally becomes around 80 a.u at 7 wt.\% of $\mathrm{CaTiO}_{3}$. Some sharp peaks due to $\mathrm{CaTiO}_{3}$ especially at 7 wt.\% of $\mathrm{CaTiO}_{3}$ NPs have appeared which can be attributable to the high content of NF. This makes the sample more rigid and thus affecting the strain rate as can be seen in a later section. The results of the present work show that it is necessary to conduct the structural study to understand the physicochemical properties of polymer composites which is a multidisciplinary field.

The surface morphology of the samples is shown in Figures 4(a)-4(e). It is displayed that pure epoxy resin (see Figure 4(a)) has many pores. These pores are not desired for mechanical properties. On the other hand, with increasing $\mathrm{CaTiO}_{3} \mathrm{NPs}$ the sizes of pores are reduced and at higher concentration of the filler, most of the pores are disappeared. The mechanical properties as can be seen in the later section may give more information regarding the effect of structure and morphology on mechanical behavior.

3.2. Mechanical Properties. Figure 5 presents the curves that compare tensile stress to tensile strain for the cured epoxy and its NCPs. It is fascinating to note the stress-strain relationship that exists between pure epoxy and epoxy NCPs as there is an increase in the tensile stress as $\mathrm{CaTiO}_{3}$ nanoparticles are added. In general, NCPs cause the tensile properties to enhance, which is not the case with neat proxy [21]. The literature reports that composites having different fillers have better tensile strengths [12-16]. It is interesting to note that at 7 wt. $\%$ of $\mathrm{CaTiO}_{3}$ NPs the sample exhibits the maximum tensile strength. These results are supported by the XRD results presented in Figure 3 and morphology appearance. Looking at the literature, it can also be said that the dispersion and shape of particles in the matrix, interfacial adhesion, matrix material strength, and other such factors determine the tensile strength of polymer composites [21]. As this research involves increased tensile strength, the stirring method with heating is indeed novel for NPs dispersion via the host epoxy resin as the viscosity is reduced. Accordingly, heating would be a good option for reducing the epoxy resin viscosity (as we have discussed earlier) as it results in the homogeneous dispersion of the filler particles. Upon loading the matrix, the NPs dispersion can withstand more tensile load of the matrix. Considering this, the composites can have better strength as the elastic deformation region is exceeded by the applied load since the load transfer is improved with the dispersed NPs [26]. There is an extension in the primary epoxy resin peaks with the increase in $\mathrm{CaTiO}_{3}$ concentration (see the XRD results, Figure 3), i.e., the d-spacing can be increased with the polymer chains' galleries experiencing NPs diffusion [27, 28].

Another part of the current work is mixing NPs with epoxy resin:fiber glass composites as well. Prior research also aimed at showing the influence of silica NPs on the mechanical properties concerning the epoxy:fiber glass composites. In the Zheng et al. [15] study, two different conditions were considered for studying how $\mathrm{SiO}_{2} \mathrm{NPs}$ affect mechanical properties of epoxy resin: (1) mixing with epoxy and (2) mixing with epoxy and fiberglass. The driving force behind it was to show the impact of the NF particles on the mechanical properties. Figures 6 and 7 show the tensile stress-strain curve and morphology appearance for epoxy resin:0.1 wt\% fiberglass incorporated with various concentrations of $\mathrm{CaTiO}_{3}$ nanoparticles. It can be seen that the tensile strength gets reduced to $16.0812 \mathrm{MPa}$ as the fiberglass was mixed with epoxy. Although, the maximum tensile strength (with 5 wt.\% $\mathrm{CaTiO}_{3}$ and $42.93 \mathrm{MPa}$ amount) was acquired by mixing the NPs having $0.2 \mathrm{wt} . \%$ fiberglass with epoxy. To the best of our knowledge, the fiberglass is impeding the homogeneous distribution of $\mathrm{CaTiO}_{3} \mathrm{NPs}_{\text {. }}$ 


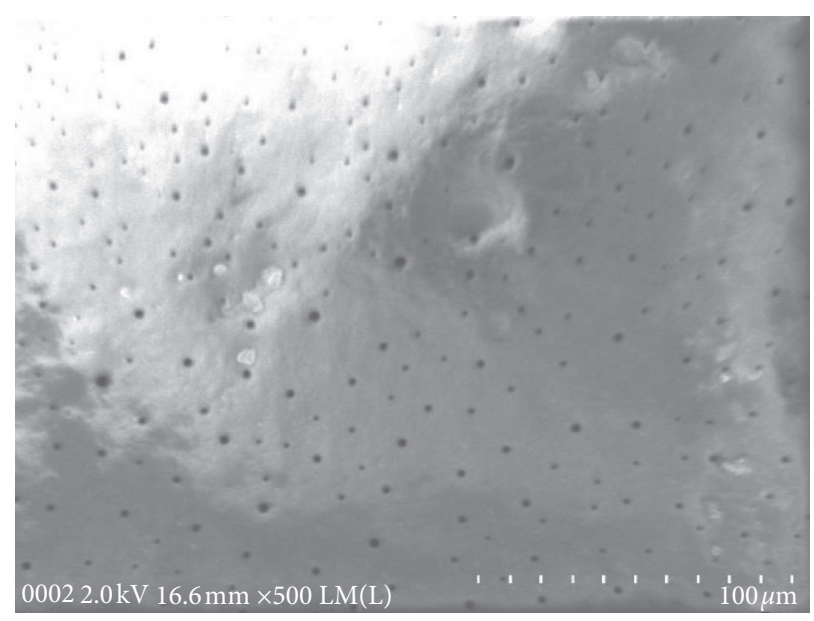

(a)

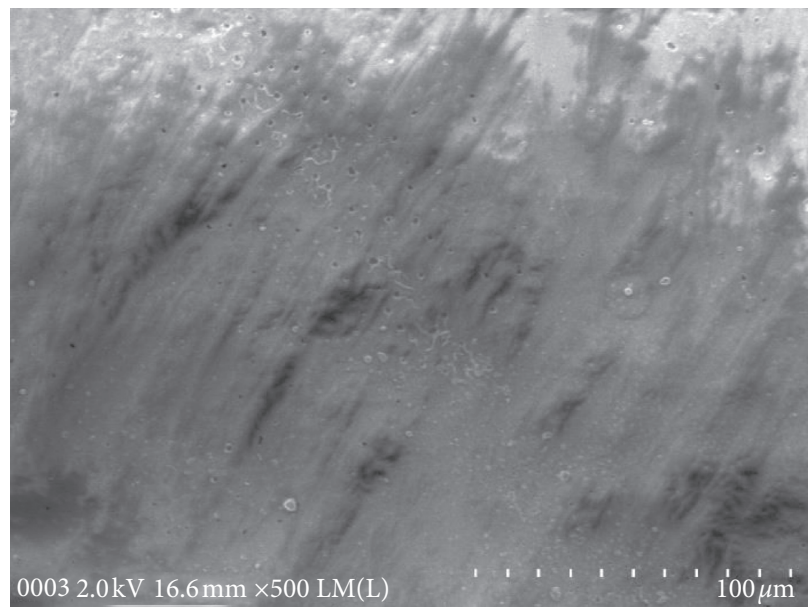

(c)

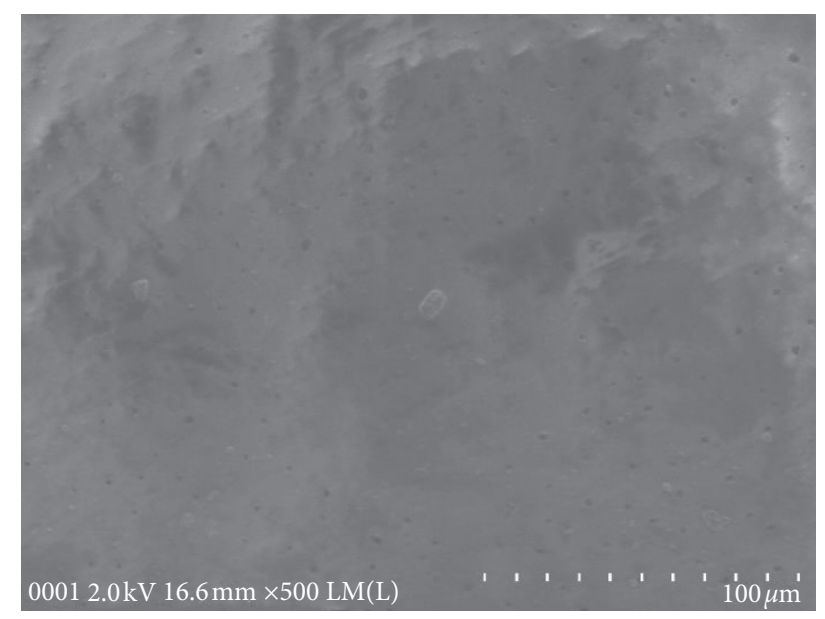

(b)

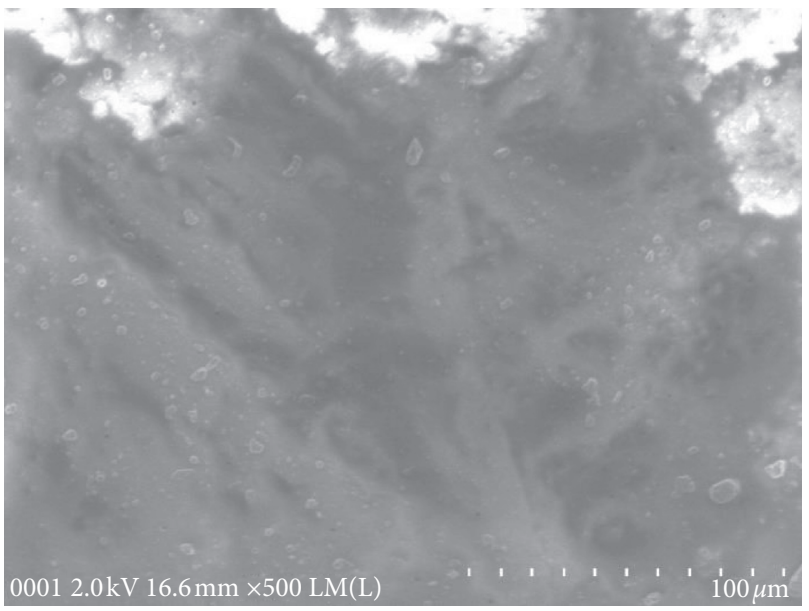

(d)

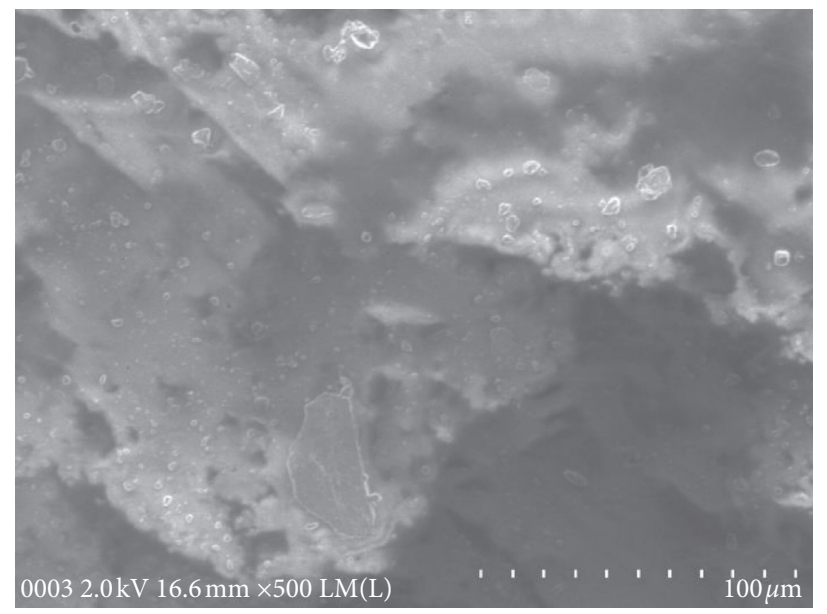

(e)

Figure 4: The FESEM image for (a) pure epoxy resin (EPR0), (b) EPR + 1 wt. $\% \mathrm{CaTiO}_{3}$, (c) $\mathrm{EPR}+3 \mathrm{wt} . \% \mathrm{CaTiO}_{3}$, (d) $\mathrm{EPR}^{+} 5$ wt.\% CaTiO 3 , and (e) $\mathrm{EPR}+7$ wt. $\% \mathrm{CaTiO}_{3}$.

Moreover, in the ternary system, the viscosity may increase and some bubbles may stay through the samples, and thus some pores may appear again. It is clear from Figure 8 that at high $\mathrm{CaTiO}_{3}$ concentration some pore has appeared especially for $0.1 \mathrm{wt} . \%$ fiber glass. There is a strong relationship between the matrix dispersion and composite's strength since prior research suggests the stress concentrations are introduced with the NPs agglomeration, which reduces the tensile strength for composites [21]. Figures 8 and 9 show the tensile stress-strain curve and morphology appearance for 


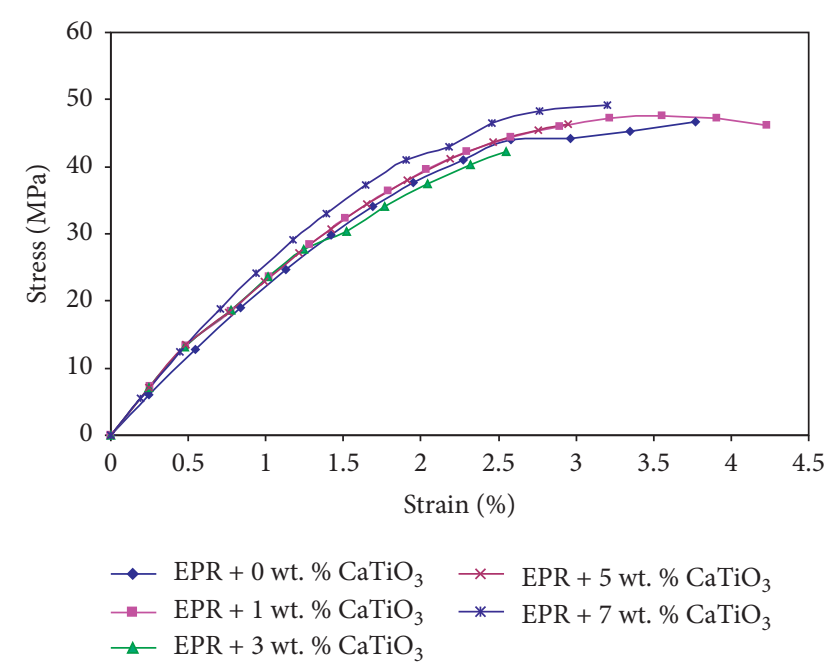

FIGURE 5: Stress-strain curves for neat epoxy resin (EPR) and epoxy resin nanocomposites.

epoxy resin:0.2 wt.\% fiber glass incorporated with various concentrations of $\mathrm{CaTiO}_{3}$ NPs. In Figure 9, it can be seen that $\mathrm{CaTiO}_{3}$ NPs are aggregated and some phase separation has appeared. These phenomena are responsible for a wide reduction in strength especially for $0.2 \mathrm{wt} . \%$ fiberglass with various concentrations of $\mathrm{CaTiO}_{3}$ NPs.

The literature revealed that mixing fillers with epoxy resin causes the tensile strength to decrease, which could be due to different potential reasons such as the NCPs having flaws. Particles having poor boundaries and the bubbles trapped when the sample was being prepared are some of these flaws. As the volume fraction of the filler increased, there could be an increment in these flaws. The nonhomogeneity of the network density of the sample is another thing that could happen. The resulting samples would end up having heterogeneity because of this high viscosity [29].

There was a comparison research that dealt with how multiwalled carbon nanotubes (MWCNTs) and graphene NPs influence the physical and mechanical properties concerning epoxy nanocomposites and various loadings of fillers. From the outcomes of the experiment, it was found that epoxy nanocomposites with graphene NPs have slightly lower mechanical properties as opposed to the epoxy nanocomposites with MWCNT [14]. It has also been seen from scratch tests that the tensile tests of $\mathrm{TiO}_{2}$ particles enable new NPs to be mixed with the epoxy composites through an ultrasonic method for NPs dispersion into the epoxy with 5, 10, 15, and 20 wt.\% [10]. Research also showed that the SiC NPs improve the mechanical properties concerning epoxy resin by $20-30 \%$ on average with various loading particles of (1.5 to 3.0) wt.\% of the resin and $1.5 \mathrm{wt} . \%$ of the loading [29]. A dynamic mechanical evaluation was used for arranging and characterizing epoxy/clay NCPs. By adding clay, it was acquired significantly increased storage modulus and modestly increased glass transition temperature [12].

Figures 10 and 11 present the elongations and force at breaks concerning the epoxy resin alongside $1 \mathrm{wt} . \%$ and 2 wt.\% of fiber glass doped with different $\mathrm{CaTiO}_{3}$ amounts. As the nanofiller is increased, there is a decrease in the elongation. The system becomes more brittle and the polymer less elongated as there is beyond a limit increase in the filler-polymer ratio [30]. From the engineering viewpoint, the rupture behavior of composite materials can be described with the key parameter that exists within elongation at break. Nevertheless, there is an inverse relationship between filler content and strain at break, as aforementioned [9]. A composite having high stiffness and strength is likely to result in decreasing elongation with increased nanocontent that NCPs demonstrate [31]. It can be seen that NF has a more positive impact on the mechanical properties of epoxy, whereas fiberglass affected the mechanical properties of epoxy negatively as opposed to those seen in the case of NF and epoxy only. The reason for this could be that fiber glasses with epoxy are not able to have a compact structure. According to the review paper by Pinto et al. [9], the dispersion of NFs through the epoxy resin can be achieved with the heating method and constant stirring. There was a significant enhancement in the mechanical properties of an epoxy resin inserted with NF (Figures 10-14). A previous study indicated that polymers and their composites form a very important class of engineering materials and are invariably used in mechanical components and their application in electronics is also wide $[32,33]$.

Table 1 presents the mechanical properties concerning the NCPs.

Nonetheless, elongation at break peaks with 1 wt.\% $\mathrm{CaTiO}_{3}$, whereas it gets to the lowest value with 5 wt.\% $\mathrm{CaTiO}_{3}$ and 0.2 wt.\% fiberglass, as it can be seen from Figure 8. The maximum force at break was $1893.5 \mathrm{~N}$ at 7 wt.\% of $\mathrm{CaTiO}_{3}$ while it is reduced upon the addition of fiberglass, as it can be seen in Figure 11. This is since the fiberglass cannot constitute a compact structure with epoxy. From Figure 12, it can be seen that epoxy-CaTiO 3 nanocomposite achieved the highest ultimate tensile strength with $49.271 \mathrm{MPa}$ at $7 \mathrm{wt} . \%$ of NPs and the lowest tensile strength with $25.95 \mathrm{MPa}$ at $5 \mathrm{wt} \% \mathrm{NPs}$ and 0.2 wt.\% fiberglass. The improved mechanical characteristics may have contributed owing to good interaction between the epoxy resin and $\mathrm{CaTiO}_{3}$ NPs. The good interfacial tension between the epoxy resin and $\mathrm{CaTiO}_{3}$ may have possibly attributed to a rise in the values of the tensile strength. The maximum Young's modulus of elasticity (i.e., 2622.904 MPa) was achieved at $0.1 \mathrm{wt} . \%$ fiberglass and 7 wt.\% $\mathrm{CaTiO}_{3}$, whereas the lowest one (i.e., $1654.747 \mathrm{MPa}$ ) was achieved at $0.2 \mathrm{wt} \%$ fiberglass and 1 wt.\% $\mathrm{CaTiO}_{3}$, as it can be seen in Figure 13. The robust adhesion between $\mathrm{CaTiO}_{3}$ nanoparticles and epoxy resin may have resulted in the powerful load-bearing capacity of the films thus raising Young's Modulus while the fiberglass with epoxy is not able to have a compact structure. The fiberglass harms the mechanical properties of epoxy. The strain rate significantly decreased upon the addition of $\mathrm{CaTiO}_{3}$ concentration. The maximum value of strain at break for NPs was $4.444 \%$ at 1 wt. $\%$ of $\mathrm{CaTiO}_{3}$ as it can be seen in Figure 14. 


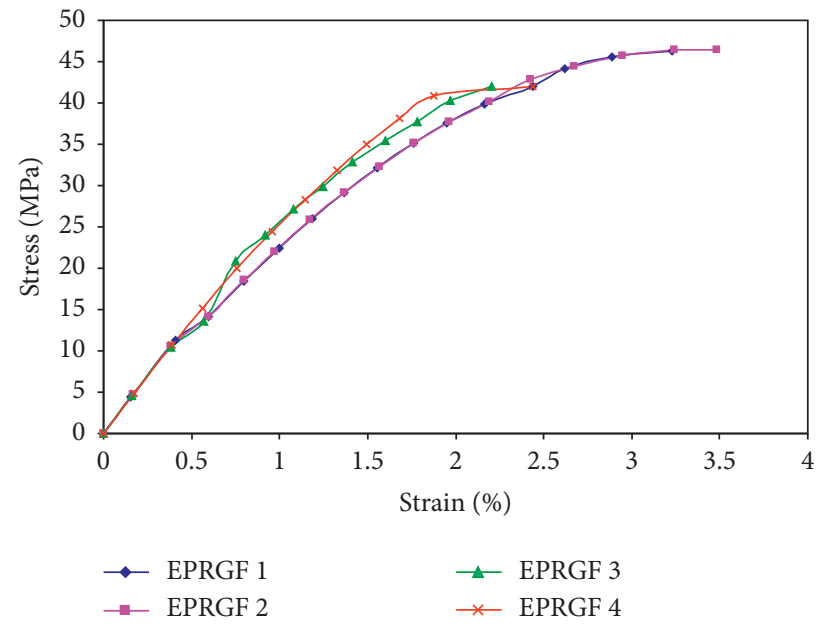

FIGURE 6: Stress-strain curves for epoxy resin: $0.1 \%$ fiberglass: $\mathrm{xCaTiO}_{3}(0.01 \leq x \leq 0.07)$ ternary composites.

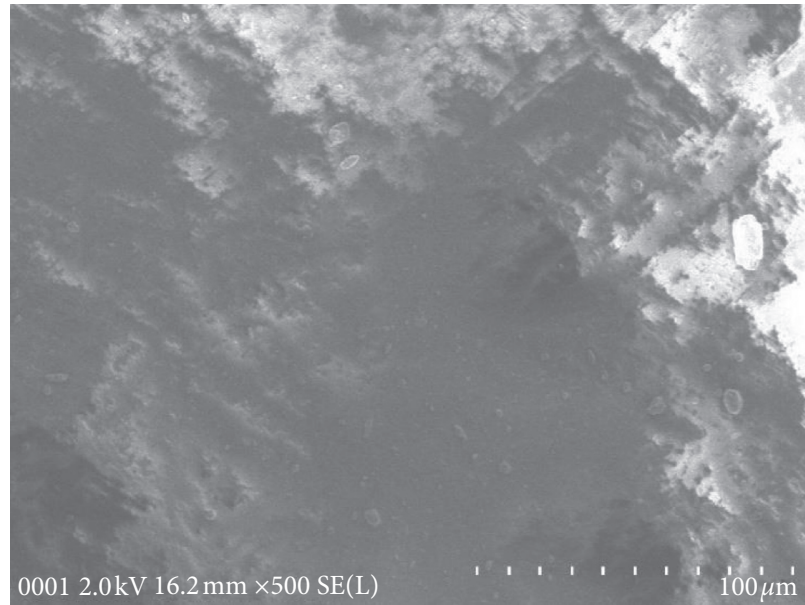

(a)

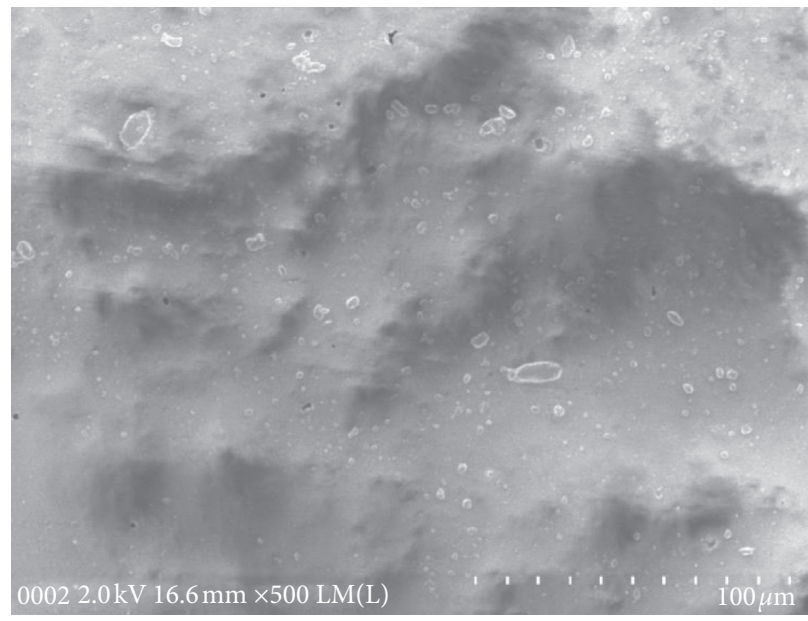

(c)

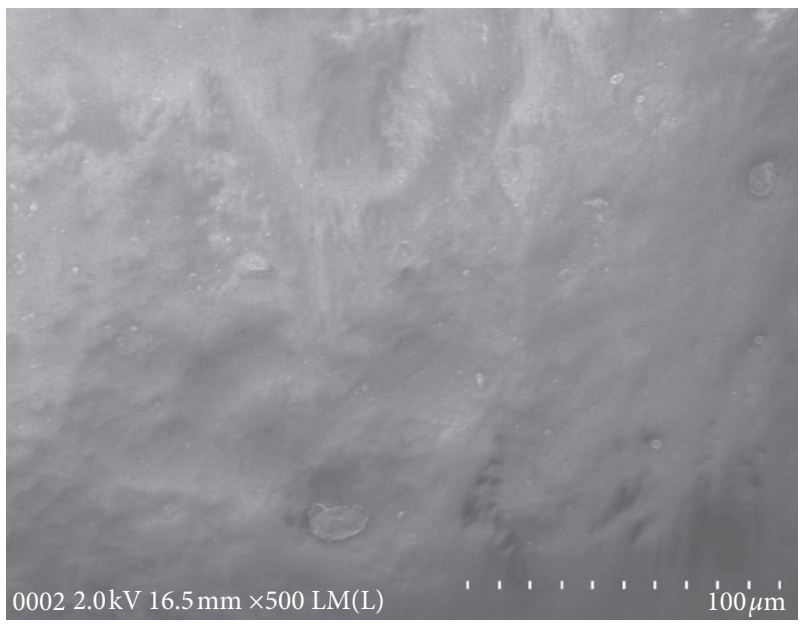

(b)

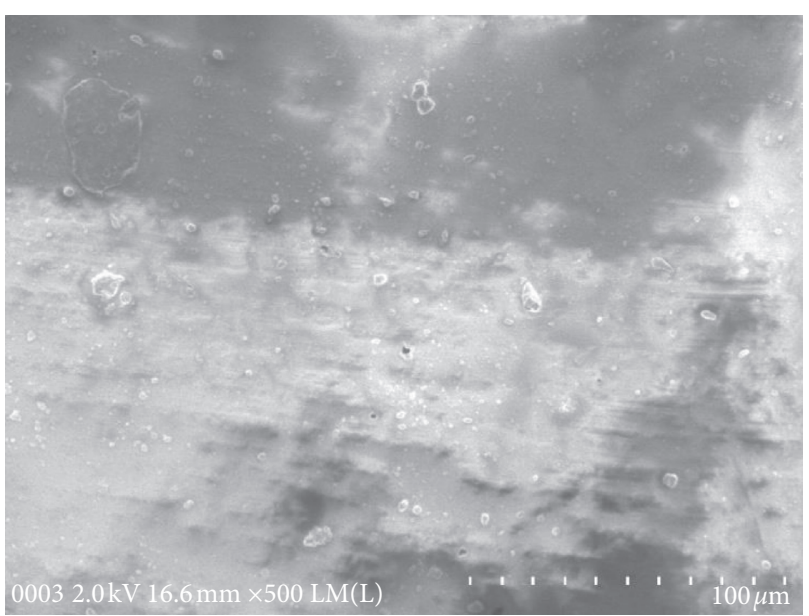

(d)

FIGURE 7: The FESEM images of epoxy resin: $0.1 \%$ fiberglass: $\mathrm{xCaTiO}_{3}(0.01 \leq x \leq 0.07)$ for (a) EPRGF 1 (b) EPRGF 2, (c) EPRGF 3, and (d) EPRGF 4. 


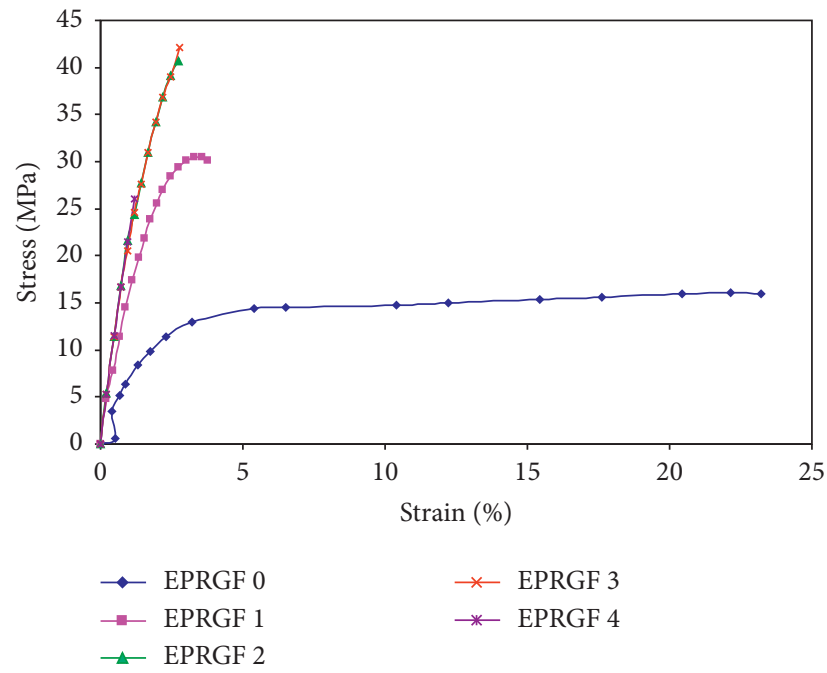

Figure 8: Stress-strain curves for epoxy resin: $0.2 \%$ fiberglass: xCaTiO3 $(0.01 \leq x \leq 0.07)$ ternary composites.

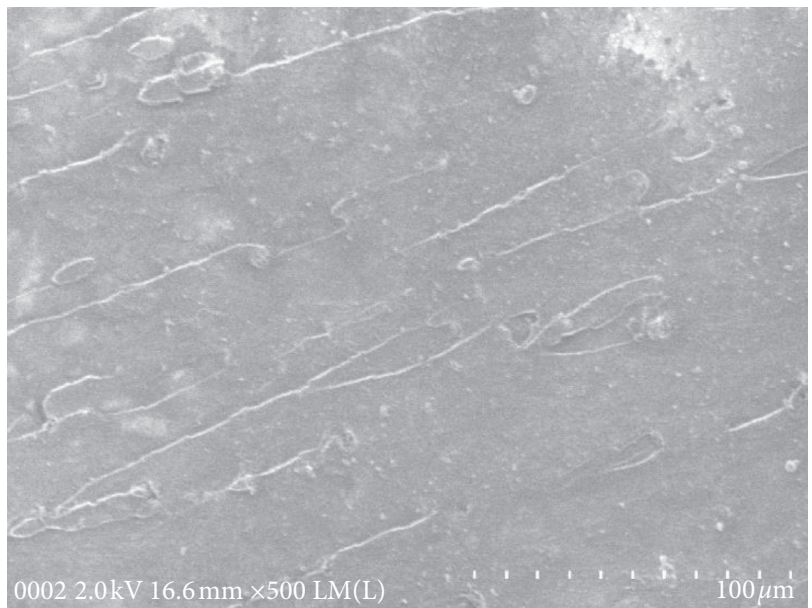

(a)

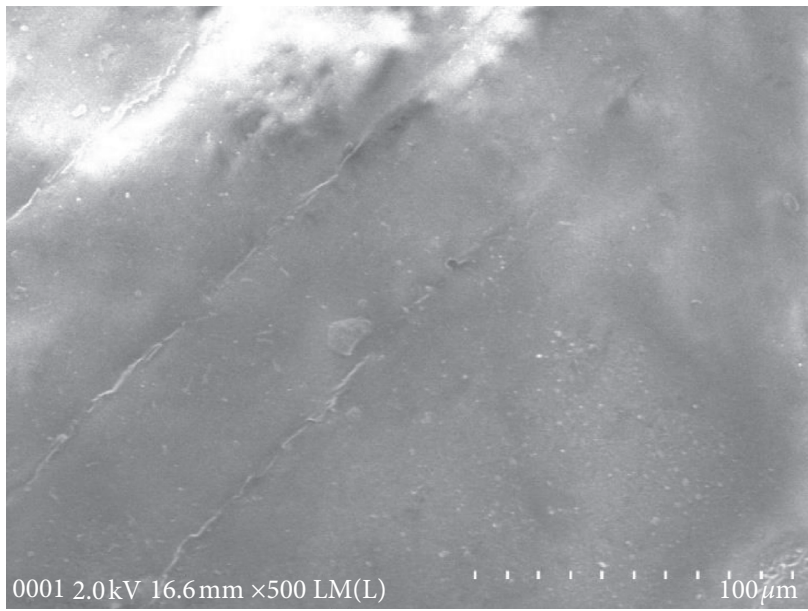

(c)

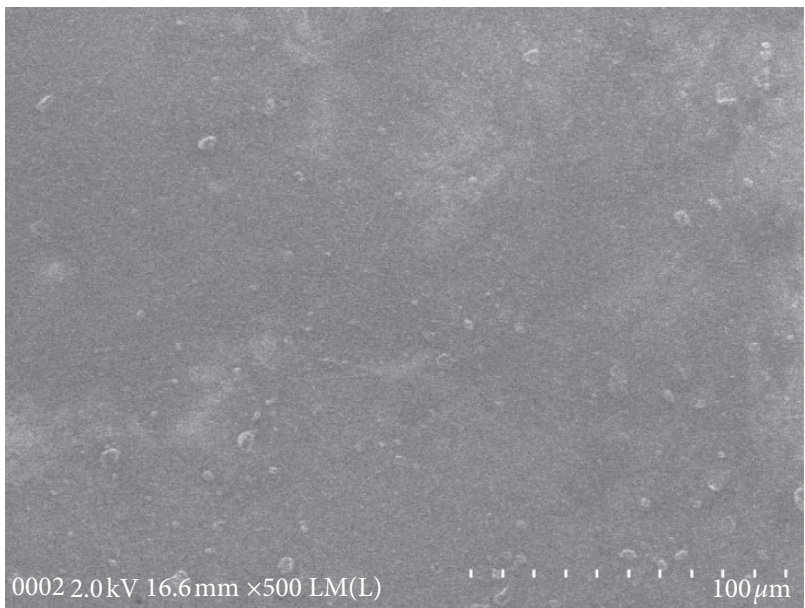

(b)

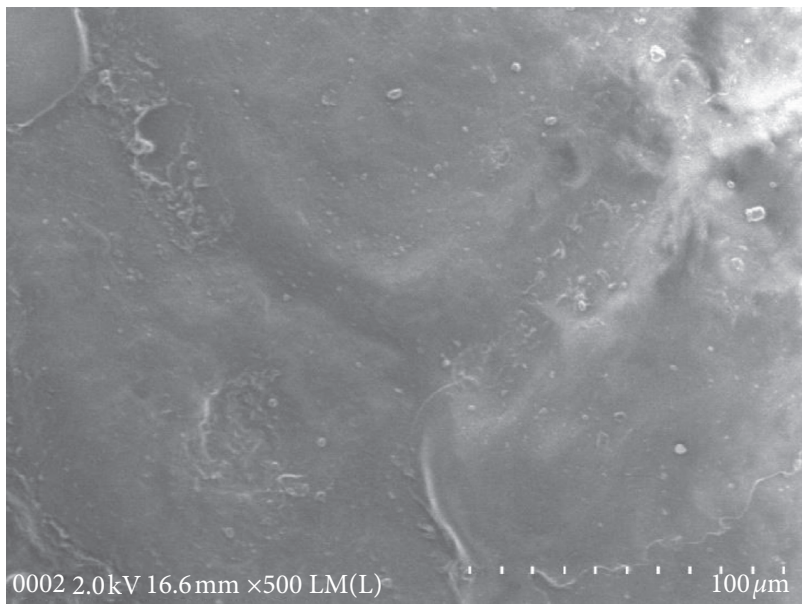

(d)

FIGURE 9: The FESEM images of epoxy resin: $0.2 \%$ fiberglass: $\mathrm{xCaTiO}_{3}(0.01 \leq x \leq 0.07$ ) for (a) EPRGF 1 (b) EPRGF 2, (c) EPRGF 3, and (d) EPRGF 4. 


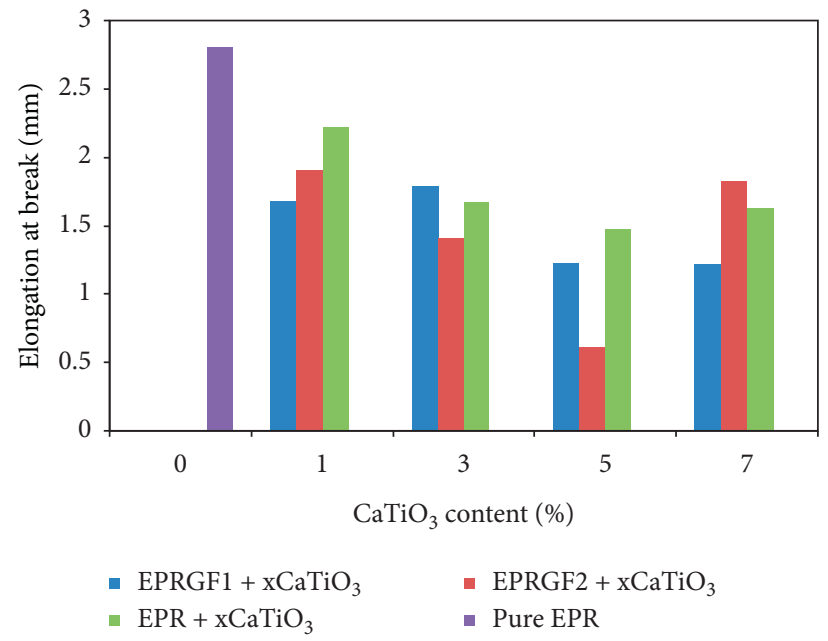

FIgURE 10: Elongation at break versus nanoparticle concentration for all the samples.

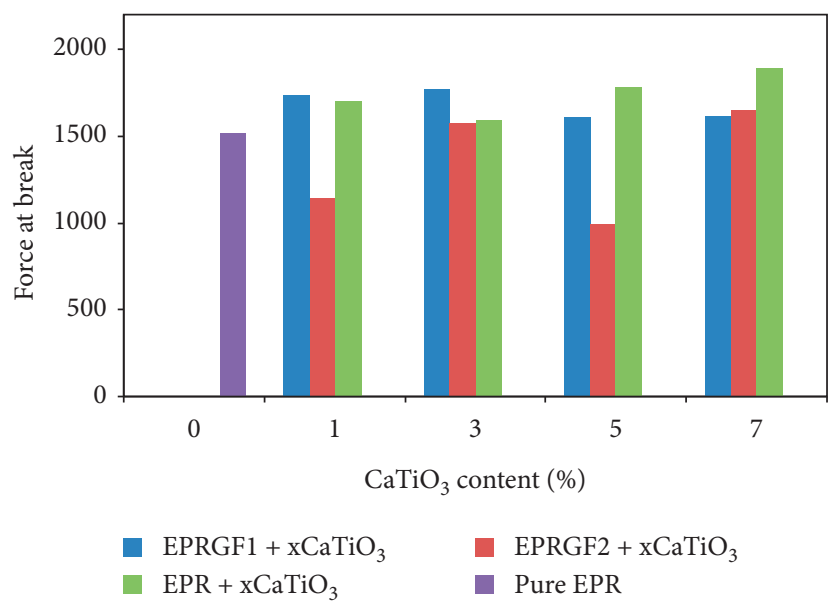

FIGURE 11: Force at break versus nanoparticle concentration for all the samples.

TABLe 1: Mechanical property of epoxy-CaTiO3 NCPs.

\begin{tabular}{|c|c|c|c|c|c|c|}
\hline $\begin{array}{l}\text { Strain at } \\
\text { break (\%) }\end{array}$ & $\begin{array}{l}\text { Young's modulus } \\
(\mathrm{MPa})\end{array}$ & $\begin{array}{c}\text { Force at break } \\
(\mathrm{N})\end{array}$ & $\begin{array}{c}\text { Elongation at break } \\
(\mathrm{mm})\end{array}$ & $\begin{array}{l}\text { Ultimate tensile } \\
\text { strength }(\mathrm{MPa})\end{array}$ & $\begin{array}{c}\mathrm{CaTiO}_{3} \text { Content } \\
\text { wt }(\%) \\
\end{array}$ & $\begin{array}{c}\text { Fiberglass content } \\
\text { wt. } \% \\
\end{array}$ \\
\hline 4.444 & 2248.488 & 1701.7 & 2.222 & 47.564 & 1 & 0 \\
\hline 3.340 & 2206.009 & 1598.0 & 1.670 & 42.207 & 3 & 0 \\
\hline 2.949 & 2346.616 & 1778.3 & 1.474 & 46.274 & 5 & 0 \\
\hline 3.246 & 2610.476 & 1893.5 & 1.623 & 49.271 & 7 & 0 \\
\hline 3.348 & 2236.816 & 1742.7 & 1.674 & 45.42 & 1 & 0.1 \\
\hline 3.586 & 2305.848 & 1776.6 & 1.793 & 46.41 & 3 & 0.1 \\
\hline 2.454 & 2326.548 & 1610.6 & 1.227 & 41.91 & 5 & 0.1 \\
\hline 2.442 & 2622.904 & 1612.7 & 1.221 & 41.97 & 7 & 0.1 \\
\hline 3.811 & 1654.747 & 1139.3 & 1.906 & 30.52 & 1 & 0.2 \\
\hline 2.816 & 2068.546 & 1572.4 & 1.408 & 40.91 & 3 & 0.2 \\
\hline 1.228 & 2253.011 & 997.5 & 0.614 & 25.95 & 5 & 0.2 \\
\hline 3.648 & 2300.663 & 1649.1 & 1.824 & 42.93 & 7 & 0.2 \\
\hline
\end{tabular}




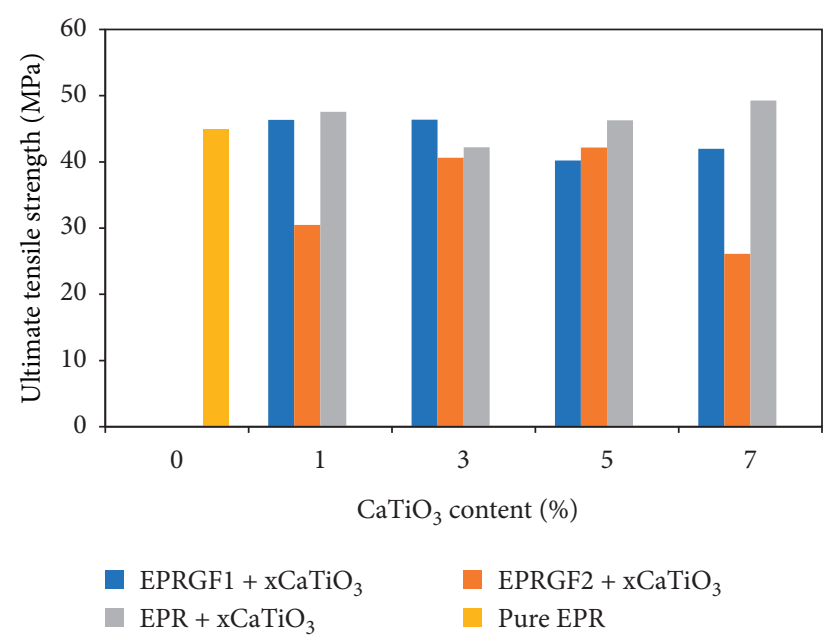

FIGURE 12: Ultimate tensile strength versus NPs concentration for all the samples.

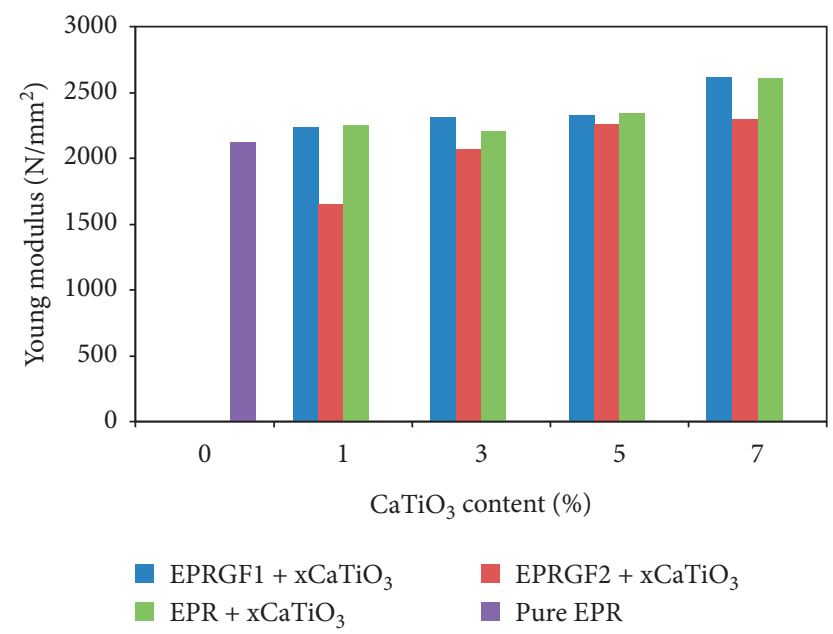

FIGURE 13: Young's modulus versus NPs concentration for all the samples.

\section{Conclusions}

In the present study, the epoxy resin-based NCPs were prepared with different amounts of NPs and glass fiber. Several sets such as pure epoxy resin, epoxy with 0.1 and 0.2 wt. \% fiberglass, and 1, 3, 5, and 7 wt.\% of $\mathrm{CaTiO}_{3}$ nanoparticles were prepared. Tensile test was performed for the different sets of specimens by using ASTM D638 and various parameters, such as Young's modulus, ultimate tensile strength, strain at break, elongation at break, and force at break, were determined. It was presented that highest ultimate tensile strength with $49.271 \mathrm{~N} / \mathrm{mm}^{2}$ was obtained at 7 wt.\% of $\mathrm{CaTiO}_{3}$. While, the maximum elongation at break was $2.222 \mathrm{~mm}$ at $1 \mathrm{wt}$.\% of $\mathrm{CaTiO}_{3}$. Furthermore, the highest value for Young's modulus of elasticity was $2622.904 \mathrm{MPa}$ at 7 wt. $\%$ of $\mathrm{CaTiO}_{3}$ and 0.1 wt.\% of fiberglass. It was also shown that the maximum value of strain at break was $4.444 \%$ at 1 wt. $\%$ of $\mathrm{CaTiO}_{3}$. Later, force at break with the highest value of $1893.5 \mathrm{~N}$ at 7 wt.\% of $\mathrm{CaTiO}_{3}$ was recorded. XRD

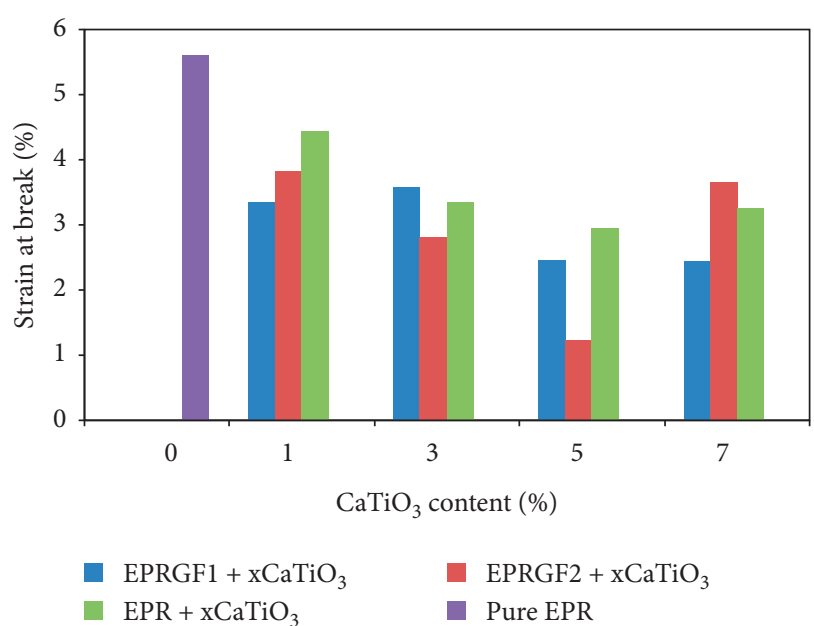

FIGURE 14: Strain at break versus NPs concentration for all the samples.

was also conducted to show how the addition of NPs significantly impacted on the epoxy structure. The FESEM images revealed a wide range of pores with various sizes for pure epoxy resin. The addition of $\mathrm{CaTiO}_{3}$ filler reduced the number of pores.

\section{Data Availability}

All the data used to support the findings of this study are included in the article.

\section{Conflicts of Interest}

The authors declare no conflicts of interest.

\section{Acknowledgments}

The authors appreciate acknowledging the financial support for this work by the Ministry of Higher Education and Scientific Research-Kurdish National Research Council (KNRC), Kurdistan Regional Government-Iraq. The financial support by the University of Sulaimani, Sulaimani Polytechnic University, and Komar Research Center (KRC) and Komar University of Science and Technology are impressively respected.

\section{References}

[1] L. Merad, B. Benyoucef, M. J. M. Abadie, and J. P. Charles, "Characterization and mechanical properties of epoxy resin reinforced with $\mathrm{TiO}_{2}$ nanoparticles," Experimental Techniques, vol. 38, no. 1, pp. 59-66, 2011.

[2] M. H. Pol and G. H. Liaghat, "Studies on the mechanical properties of composites reinforced with nanoparticles," Polymer Composites, vol. 38, no. 1, pp. 205-212, 2017.

[3] F. Liu, S. Deng, and J. Zhang, "Mechanical properties of epoxy and its carbon fiber composites modified by nanoparticles," Journal of Nanomaterials, vol. 2017, Article ID 8146248, 9 pages, 2017.

[4] L. R. Xu, V. Bhamidipati, W.-H. Zhong et al., "Mechanical property characterization of a polymeric nanocomposite 
reinforced by graphitic nanofibers with reactive linkers," Journal of Composite Materials, vol. 38, no. 18, pp. 1563-1582, 2004.

[5] M. F. Uddin and C. T. Sun, "Improved dispersion and mechanical properties of hybrid nanocomposites," Composites Science and Technology, vol. 70, no. 2, pp. 223-230, 2010.

[6] M. Megahed, A. A. Megahed, and M. A. Agwa, "Mechanical properties of on/off-axis loading for hybrid glass fiber reinforced epoxy filled with silica and carbon black nanoparticles," Materials Technology, vol. 33, no. 6, pp. 398-405, 2018.

[7] H. Fischer, "Polymer nanocomposites: from fundamental research to specific applications," Materials Science and Engineering: $C$, vol. 23, no. 6-8, pp. 763-772, 2003.

[8] C. Monteserín, M. Blanco, E. Aranzabe et al., "Effects of graphene oxide and chemically-reduced graphene oxide on the dynamic mechanical properties of epoxy amine composites," Polymers, vol. 9, no. 12, p. 449, 2017.

[9] D. Pinto, L. Bernardo, A. Amaro, and S. Lopes, "Mechanical properties of epoxy nanocomposites using titanium dioxide as reinforcement-a review," Construction and Building Materials, vol. 95, pp. 506-524, 2015.

[10] C. B. Ng, L. S. Schadler, and R. W. Siegel, "Synthesis and mechanical properties of $\mathrm{TiO}_{2}$-epoxy nanocomposites," Nanostructured Materials, vol. 12, no. 1-4, pp. 507-510, 1999.

[11] B. Ramezanzadeh, M. M. Attar, and M. Farzam, "Effect of $\mathrm{ZnO}$ nanoparticles on the thermal and mechanical properties of epoxy-based nanocomposite," Journal of Thermal Analysis and Calorimetry, vol. 103, no. 2, pp. 731-739, 2011.

[12] D. Ratna, N. R. Manoj, R. Varley, R. K. Singh Raman, and G. P. Simon, "Clay-reinforced epoxy nanocomposites," Polymer International, vol. 52, no. 9, pp. 1403-1407, 2003.

[13] A. Allaoui, S. Bai, H. M. Cheng, and J. B. Bai, "Mechanical and electrical properties of a MWNT/epoxy composite," Composites Science and Technology, vol. 62, no. 15, pp. 1993-1998, 2002.

[14] M. R. Zakaria, M. H. Abdul Kudus, H. M. Akil, and M. Z. Mohd Thirmizir, "Comparative study of graphene nanoparticle and multiwall carbon nanotube filled epoxy nanocomposites based on mechanical, thermal and dielectric properties," Composites Part B: Engineering, vol. 119, pp. 57-66, 2017.

[15] Y. Zheng, R. Ning, and Y. Zheng, "Study of SiO2 nanoparticles on the improved performance of epoxy and fiber composites," Journal of Reinforced Plastics and Composites, vol. 24, no. 3, pp. 223-233, 2005.

[16] A. Omrani, L. C. Simon, and A. A. Rostami, "The effects of alumina nanoparticle on the properties of an epoxy resin system," Materials Chemistry and Physics, vol. 114, no. 1, pp. 145-150, 2009.

[17] G. Qian, Z. Jian, X. Pan, and F. Berto, "In-situ investigation on fatigue behaviors of Ti-6Al-4V manufactured by selective laser melting," International Journal of Fatigue, vol. 133, Article ID 105424, 2020.

[18] G. Qian and W.-S. Lei, "A statistical model of fatigue failure incorporating effects of specimen size and load amplitude on fatigue life," Philosophical Magazine, vol. 99, no. 17, pp. 2089-2125, 2019.

[19] B. Li, V. Krsjak, J. Degmova et al., "Positron annihilation spectroscopy study of vacancy-type defects in He implanted polycrystalline $\alpha$-SiC," Journal of Nuclear Materials, vol. 535, p. $152180,2020$.

[20] B. Li, Z. Wang, K. Wei et al., "Evaluation of helium effect on irradiation hardening in F82H, ODS, SIMP and T91 steels by nano-indentation method," Fusion Engineering and Design, vol. 142, pp. 6-12, 2019.

[21] T. khezri, M. Sharif, and B. Pourabas, "Polythiophene-graphene oxide doped epoxy resin nanocomposites with enhanced electrical, mechanical and thermal properties," RSC Advances, vol. 6, no. 96, pp. 93680-93693, 2016.

[22] M. L. Costa, L. C. Pardini, and M. C. Rezende, "Influence of aromatic amine hardeners in the cure kinetics of an epoxy resin used in advanced composites," Materials Research, vol. 8, no. 1, pp. 65-70, 2005.

[23] A. M. Amaro, L. Bernardo, D. G. Pinto, S. Lopes, and J. Rodrigues, "The influence of curing agents in the impact properties of epoxy resin nanocomposites," Composite Structures, vol. 174, pp. 26-32, 2017.

[24] S. B. Aziz, "Role of dielectric constant on ion transport: reformulated Arrhenius equation," Advances in Materials Science and Engineering, vol. 2016, Article ID 2527013, 11 pages, 2016.

[25] S. B. Aziz and Z. A. Zul Hazrin, "Ion-transport study in nanocomposite solid polymer electrolytes based on chitosan: electrical and dielectric analysis," Journal of Applied Polymer Science, vol. 132, no. 15, p. 41774, 2015.

[26] F. H. Goiny, J. Nastalczyk, Z. Roslaniec, and K. Schulte, "Surface modified multi-walled carbon nanotubes in CNT/ epoxy-composites," Chemical Physics Letters, vol. 370, p. 820, 2003.

[27] W. Widia, "Amir, aidah jumahat, anizah kalam, characterization of nanoclay-modified epoxy polymers using X-RayDiffraction analysis," Applied Mechanics and Materials, vol. 699, pp. 175-180, 2015.

[28] S. M. Mousavi, O. Arjmand, S. A. Hashemi, and N. Banaei, "Modification of the epoxy resin mechanical and thermal properties with silicon acrylate and montmorillonite nanoparticles," Polymers from Renewable Resources, vol. 7, no. 3, pp. 101-114, 2016.

[29] K. Wang, L. Chen, J. Wu, M. L. Toh, A. F. C. He, and A. F. Yee, "Epoxy nanocomposites with highly exfoliated clay: mechanical properties and fracture mechanisms," Macromolecules, vol. 38, no. 3, pp. 788-800, 2005.

[30] A. Yasmin and I. M. Daniel, "Mechanical and thermal properties of graphite platelet/epoxy composites," Polymer, vol. 45, no. 24, pp. 8211-8219, 2004.

[31] N. Hameed, L. F. Dumee, F. Allioux et al., "Graphene based room temperature fexible nanocomposites from permanently cross-linked networks," Scientific Reports, vol. 8, no. 1, p. 2803, 2018.

[32] B. N. Ravi Kumar, B. Suresha, and M. Venkataramareddy, "Effect of particulate fillers on mechanical and abrasive wear behaviour of polyamide 66/polypropylene nanocomposites," Materials \& Design, vol. 30, no. 9, pp. 3852-3858, 2009.

[33] S. Pan and Z. Zhang, "Triboelectric effect: a new perspective on electron transfer process," Journal of Applied Physics, vol. 122, no. 14, p. 144302, 2017. 